\title{
Protective effects of glycerol and xylitol in keratinocytes exposed to hyperosmotic stress
}

This article was published in the following Dove Press journal:

Clinical, Cosmetic and Investigational Dermatology

\author{
Edit Szél ${ }^{1}$ \\ Judit Danis ${ }^{2}$ \\ Evelin Sörés' \\ Dániel Tóth ${ }^{3}$ \\ Csilla Korponyai ${ }^{1}$ \\ Döníz Degovics' \\ János Prorok ${ }^{3}$ \\ Károly Acsai ${ }^{3}$ \\ Shabtay Dikstein ${ }^{4}$ \\ Lajos Kemény ${ }^{1,2}$ \\ Gábor Erős' \\ 'Department of Dermatology and \\ Allergology, University of Szeged, Szeged, \\ Hungary; ${ }^{2}$ MTA-SZTE Dermatological \\ Research Group, Szeged, Hungary; \\ ${ }^{3}$ Department of Pharmacology and \\ Pharmacotherapy, University of Szeged, \\ Szeged, Hungary; ${ }^{4}$ Unit of Cell \\ Pharmacology, Hebrew University, \\ Jerusalem, Israel
}

Purpose: Our goal was to study whether glycerol and xylitol provide protection against osmotic stress in keratinocytes.

Methods: The experiments were performed on HaCaT keratinocytes. Hyperosmotic stress was induced by the addition of sorbitol (450, 500 and $600 \mathrm{mOsm})$. Both polyols were applied at two different concentrations (glycerol: $0.027 \%$ and $0.27 \%$, xylitol: $0.045 \%$ and $0.45 \%$ ). Cellular viability and cytotoxicity were assessed, intracellular $\mathrm{Ca}^{2+}$ concentration was measured, and the RNA expression of inflammatory cytokines was determined by means of PCR. Differences among groups were analyzed with one-way ANOVA and Holm-Sidak post-hoc test. When the normality test failed, Kruskal-Wallis one-way analysis of variance on ranks, followed by Dunn's method for pairwise multiple comparison was performed.

Results: The higher concentrations of the polyols were effective. Glycerol ameliorated the cellular viability while xylitol prevented the rapid $\mathrm{Ca}^{2+}$ signal. Both polyols suppressed the expression of IL- $1 \alpha$ but only glycerol decreased the expression of IL-1 $\beta$ and NFAT5.

Conclusions: Glycerol and xylitol protect keratinocytes against osmotic stress. Despite their similar chemical structure, the effect of these polyols displayed differences. Hence, joint application of glycerol and xylitol may be a useful therapeutic approach for different skin disorders.

Keywords: hyperosmotic stress, glycerol, xylitol, intracellular calcium concentration

\section{Introduction}

Local hyperosmotic condition is revealed to be associated with several inflammatory disorders (eg, corneal inflammation in dry eyes syndrome, inflammatory bowel disease, etc.). ${ }^{1}$ Presumably, a local hyperosmotic challenge may contribute to the development of irritant contact dermatitis (ICD). ICD is a non-immunologic, nonspecific inflammatory skin disease induced by physical, mechanical or chemical factors and accompanied by impaired barrier function. This results in increased skin permeability and transepidermal water loss (TEWL). ${ }^{2}$ Water evaporation can lead to a higher osmotic pressure in the superficial layer of the skin. Furthermore, hyperosmolarity induces various intracellular responses in different types of cells and reduces cellular viability. ${ }^{3-7}$ It has been described that a hyperosmotic stimulus elevates intracellular calcium $\left(\mathrm{Ca}^{2+}\right)$ concentration in $\mathrm{HaCaT}$ keratinocytes. ${ }^{6,8}$ Although its exact molecular mechanism has not yet been revealed, it has been shown that $\mathrm{Ca}^{2+}$ is derived from both intra- and extracellular compartments. ${ }^{6,8}$

Keratinocytes are known to produce pro-inflammatory cytokines when exposed to osmotic stress. ${ }^{9}$ At mRNA level, expression of tumor necrosis factor-alpha (TNF- $\alpha$ ), interleukin 1-beta (IL-1 $\beta$ ), IL- $8,{ }^{3}$ IL- $6{ }^{4}$ and nuclear factor of activated
Correspondence: Edit Szél Department of Dermatology and Allergology, University of Szeged, Korányi fasor 6., Szeged 6720, Hungary

Tel +36 707761104

Fax +36 62545954

Email szeledit@hotmail.com 
T cells 5 (NFAT5) ${ }^{5}$ was found to be higher in epithelial cells. In normal human epidermal keratinocytes, elevated mRNA expression of TNF- $\alpha$, IL-1 $\beta$, IL- 6 and IL- 8 was observed. $^{9}$

NFAT5 is a principal transcription factor involved in water homeostasis during normal cornification ${ }^{10}$ and activated by hyperosmotic stress; ${ }^{5}$ however, its regulation by $\mathrm{Ca}^{2+}$ signals is equivocal. ${ }^{11-13}$ Local hyperosmotic stress of the skin activates NFAT5 in macrophages ${ }^{1}$ thereby intensifying the electrolyte clearance via lymphatic vessels. ${ }^{14}$

Under experimental conditions, different methods are used to induce hyperosmotic stress. Sodium chloride is usually used for this aim $^{3-5}$ and non-ionic organic agents such as sorbitol ${ }^{9}$ and sucrose ${ }^{4}$ can also be applied on keratinocyte cultures.

Glycerol and xylitol have well-known beneficial effects on the skin ${ }^{15-18}$ but their role as osmolytes has not yet been fully clarified. It has been revealed that glycerol composes the principal osmolyte system of several bacterial species ${ }^{19}$ while xylitol inhibits inflammatory cytokine expression. ${ }^{20}$ Previously, we have shown the anti-inflammatory and antiirritant effects of glycerol and xylitol. ${ }^{16-18}$ Other in vitro experiments have revealed that glycerol suppresses human leukocyte antigen-DR (HLA-DR) mRNA level and xylitol upregulates filaggrin mRNA expression. ${ }^{21}$

The aim of the present study was to investigate whether glycerol and xylitol provide protection against hyperosmotic stress in vitro. Their effects on cellular viability and cytotoxicity, intracellular $\mathrm{Ca}^{2+}$ concentration, expression of pro-inflammatory cytokines and cellular viability were studied.

\section{Materials and methods}

\section{Cell culture}

HaCaT cells kindly provided by Dr N. E. Fusenig (Heidelberg, Germany) were cultured in Dulbecco's modified Eagle's medium containing $4.5 \mathrm{~g} / \mathrm{L}$ glucose, $1.8 \mathrm{mM} \mathrm{Ca}^{2+}$ (DMEM-HG) supplemented with $10 \%$ fetal bovine serum (FBS), $2 \mathrm{mM}$ L-glutamine, $100 \mathrm{U} / \mathrm{mL}$ penicillin, $100 \mu \mathrm{g} / \mathrm{mL}$ streptomycin, $0.25 \mu \mathrm{g} / \mathrm{mL}$ amphotericin $\mathrm{B}$ and grown at $37^{\circ} \mathrm{C}$ in a humidified atmosphere containing $5 \% \mathrm{CO}_{2}$. Three to four days after plating, cells were collected from semi-confluent cultures by $5-10$ mins trypsinization ( $0.25 \%$ trypsin-EDTA solution). The proteolic digestion was stopped by FBS and the cells were sedimented (10 mins, $\left.4^{\circ} \mathrm{C}, 1,500 \mathrm{~g}\right)$ and resuspended in the medium for further use. Cellular viability was determined by the trypan blue exclusion test. The experiments were performed on cultures, where trypan blue was excluded from $95 \%$ of the cells.

\section{Preparation of the treating media}

For osmolarity measurement, Model 5600 Vapro ${ }^{\circledR}$ Vapor Pressure Osmometer (Dieren, The Netherlands) was used. The basal osmolarity of the serum-free DMEM-HG medium was 338 mOsm. Media contained 3 or $30 \mathrm{mM}$ polyols, respectively, which was equivalent to 0.027 or $0.27 \mathrm{w} / \mathrm{w} \%$ glycerol and 0.045 or $0.45 \mathrm{w} / \mathrm{w}$ $\%$ xylitol. ${ }^{21}$ The osmolarity of these solutions was also measured. The final osmolarity of 450, 500 and 600 mOsm was reached by the addition of the appropriate amount of $1.83 \mathrm{M}$ sorbitol stock solution. Serum-free DMEM-HG media containing only glycerol, xylitol or sorbitol in concentrations mentioned above, respectively, were also applied.

\section{Cellular viability and cytotoxicity}

Cells were seeded into 96-well culture plates at a density of $10^{4}$ cells/well in DMEM-HG supplemented with the appropriate agents detailed above, and serumstarved $24 \mathrm{hrs}$ before any treatments. For $60 \mathrm{mins}$, cells were incubated with or without $0.27 \%$ glycerol or $0.45 \%$ xylitol in serum-free DMEM-HG, followed by incubation with 450,500 or $600 \mathrm{mOsm}$ culture medium with or without $0.27 \%$ glycerol or $0.45 \%$ xylitol for $24 \mathrm{hrs}$. Experiments were carried out in triplicates, and data are presented as the means of three experiments.

For the cell viability assay, $0.5 \%$ MTT (3-(4,5-dimethylthiazol-2-yl)-2,5-diphenyltetrazolium bromide) solution was added to the cells at $37^{\circ} \mathrm{C}$ for $4 \mathrm{hrs}$, and then the formazan crystals were solubilized and the optical density (OD) was measured at $540 \mathrm{~nm}$ by a Multiscan Ex spectrophotometer (Thermo Labsystems, Beverly, Massachusetts, USA) and Ascent Software (Thermo Fisher Scientific, Waltham, Massachusetts, USA). The absorbance rate was compared to untreated samples and represented as percentage rate of living cells.

Cytotoxicity was assessed by using the Cytotoxicity Detection Kit PLUS (Roche Diagnostics, Risch, Switzerland) according to the manufacturer's instructions. Briefly, released lactate dehydrogenase (LDH) was quantified from the supernatant by a colorimetric method and optical density was measured at $492 \mathrm{~nm}$. Measured values 
were corrected with the background values of the cell-free culture medium. Results are presented of \% in cytotoxicity, where lysed cells correspond to $100 \%$ cytotoxicity.

\section{Determination of changes in $\left[\mathrm{Ca}^{2+}\right]_{i}$}

HaCaT keratinocytes were plated onto $13 \mathrm{~mm}$ diameter uncoated sterile coverslips (VWR, Radnor, Pennsylvania, USA) and were left to attach and proliferate for $24 \mathrm{hrs}$. Coverslips with the attached cells were transferred and incubated in Tyrode's solution (144 mM NaCl, $0.4 \mathrm{mM}$ $\mathrm{NaH}_{2} \mathrm{PO}_{4}, 4 \mathrm{mM} \mathrm{KCl}, 0.53 \mathrm{mM} \mathrm{MgSO}, 1.8 \mathrm{mM} \mathrm{CaCl}_{2}$, $5.5 \mathrm{mM}$ glucose and $5 \mathrm{mM}$ HEPES, $\mathrm{pH}=7.4$ ). HaCaT cells were loaded by incubation for 20 mins with the acetoxymethyl ester (AM) form of a single wavelength calciumsensitive fluorescent dye (Fluo-4, Molecular Probes Inc., Eugene, Oregon, USA, $5 \mu \mathrm{M}$ from a stock of $1 \mathrm{mM}$ in DMSO $+20 \%$ pluronic acid Pluronic F-127 SigmaAldrich, Saint Louis, Missouri, USA and $6.25 \mathrm{nM} / \mathrm{mL}$ Probenecid, Molecular Probes Inc., Eugene, Oregon, USA) at room temperature in dark. After incubation period, the cells were washed in indicator-free Tyrode's solution to remove any dye. The technique for intracellular calcium detection was based on established procedures described earlier. ${ }^{22}$ Subsequently, cells were incubated for 30 mins with $0.027 \%$ or $0.27 \%$ glycerol and $0.045 \%$ or $0.45 \%$ xylitol $^{21}$ in Tyrode solution, respectively.

Optical measurements were performed using a Zeiss Axiovert 100 microscope (Zeiss, Oberkochen, Germany) equipped with a xenon lamp and used in epifluorescent mode at 100x magnitude. The coverslips were placed into a low volume imaging chamber (Warner Instruments, Hamden, Connecticut, USA) $\left(37^{\circ} \mathrm{C}\right)$ at the microscope stage and cells were superfused with Tyrode alone for at least 10 mins (control period). Hyperosmotic stimulus was added to the cells in rapid perfusion $(2-3 \mu \mathrm{L} / \mathrm{sec})$ of $450 \mathrm{mOsm}$ sorbitol, followed by the addition of $30 \mathrm{nmol} / \mathrm{mL}$ A23187 ionophor in Tyrode. Cells in the $75 \times 75 \mu \mathrm{m}$ frame were illuminated at $485 \mathrm{~nm}$ and the emitted light was recorded at $535 \mathrm{~nm}$. Images of relative fluorescence intensity of a cell group (3-5 cells/ group) were collected in 8-10 independent experiments per treatment group with the Mintron 7266pd Color CCD Camera (New Taipei City, Taiwan). Raw data were analyzed with WinWCP V4.5.0 (Glasgow, Scotland) and Clampfit 10.6 (San Jose, California, USA) softwares.

Calibration was performed by the $\left[\mathrm{Ca}^{2+}\right]_{\mathrm{i}}=\mathrm{Kd}$ (F-Fmin)/(Fmax-F) method ${ }^{23}$ where $\left[\mathrm{Ca}^{2+}\right]_{\mathrm{i}}$ is the intracellular $\mathrm{Ca}^{2+}$ concentration, $\mathrm{Kd}$ is the dissociation constant $(345 \mathrm{nM}), \mathrm{F}$ is the fluorescence intensity evoked with the hyperosmotic stimulus, Fmin values were developed from corrected fluorescence intensity before osmotic stress and Fmax values were derived from the maximal fluorescent response after the addition of the ionophor solution. Background correction was calculated with the autofluorescence of unloaded cells and the decrease of fluorescence intensity in untreated cells caused by bleaching or dye efflux. For representative figures, $\Delta \mathrm{Ca}^{2+}=\Delta \mathrm{F} / \mathrm{F}=(\mathrm{F}-$ Frest)/Frest) was calculated. ${ }^{23}$

\section{Real-time polymerase chain reaction (RT-PCR)}

Cells were seeded into 6-well plates at a density of $2 \times 10^{5}$ cells $/ \mathrm{mL}$ and serum-starved overnight. Cells were preincubated for 60 mins with $0.27 \%$ glycerol or $0.45 \%$ xylitol, followed by incubation with $450 \mathrm{mOsm}$ sorbitol for 2 and $6 \mathrm{hrs}^{3-5}$ Untreated or sorbitol-treated cells served as negative or positive controls, respectively. Total RNA was isolated using TRIzol reagent (SigmaAldrich, Saint Louis, Missouri, USA) according to the manufacturer's instructions. To avoid DNA contamination, DNAse treatment was performed and intron-spanning assays were used. cDNA was synthesized from $1 \mu \mathrm{g}$ total RNA using the iScript cDNA Synthesis Kit (Bio-Rad Laboratories, Hercules, California, USA). Real-time RTPCR experiments were carried out with the Universal Probe Library system (Roche Diagnostics, Risch, Switzerland) using TaqMan probe-based assays and a C1000 Touch Thermal Cycler (Bio-Rad Laboratories, Hercules, California, USA). The applied primers are listed in Table 1. The expression of each gene was normalized to the 18S rRNA gene, and relative mRNA levels were calculated by the $\Delta \Delta \mathrm{Ct}$ method, compared to untreated, time-matched control samples.

\section{Statistical analysis}

Data analysis was performed with SigmaStat for Windows 11.0 software (Jandel Scientific, San Rafael, California, USA). Differences among groups were analyzed with oneway ANOVA and Holm-Sidak post-hoc test and data are presented as mean $(\mathrm{m})$ values with standard deviation (SD). When the normality test failed, Kruskal-Wallis oneway analysis of variance on ranks, followed by Dunn's method for pairwise multiple comparison was performed. In such cases, median values (M) with 25 th and 75 th percentiles (25p and $75 \mathrm{p}$, respectively) are given. $P<0.05$ was considered statistically significant. 
Table I Known sequences of primer pairs and probes used for RT-PCR

\begin{tabular}{|l|l|l|}
\hline & Sense & Antisense \\
\hline TNF- $\alpha$ & CAGCCTCTTCTCCTTCCTGAT & GCCAGAGGGCTGATTAGAGA \\
\hline IL-I $\alpha$ & AACCAGTGCTGCTGAAGGA & TTCTTAGTGCCGTGAGTTTCC \\
\hline IL-I $\beta$ & AAAGCTTGGTGATGTCTGGTC & AAAGGACATGGAGAACACCACT \\
\hline IL-6 & CAGGAGCCCAGCTATGAACT & GAAGGCAGCAGGCAACAC \\
\hline NFAT5 & TCAGACAAGCGGTGGTGA & AGGGAGCTGAAGAAGCATCA \\
\hline IL-8 & TaqMan® Gene Expression Assay, Thermo Scientific \\
\hline
\end{tabular}

\section{Results}

\section{Glycerol of $0.27 \%$ but not xylitol} ameliorated the viability of $\mathrm{HaCaT}$ cells exposed to hyperosmotic stress

During a period of $24 \mathrm{hrs}$, osmotic stresses of 450 and 500 mOsm did not influence cellular viability, and the average cytotoxicity values were negligible. However, $600 \mathrm{mOsm}$ sorbitol significantly reduced viability. The reduction was also considerable in the additional polyol-treated groups, but glycerol treatment resulted in significantly higher viability as compared to the positive control (DMEM-HG +600 mOsm sorbitol) group. $0.45 \%$ xylitol failed to improve the survival of the cells. The average cytotoxicity value of the $0.27 \%$ glycerol $+600 \mathrm{mOsm}$ sorbitol-treated group was somewhat lower but did not differ significantly from that of its control (DMEM-HG+600 mOsm sorbitol) group. Viability and cytotoxicity in groups exposed to $0.27 \%$ glycerol and $0.45 \%$ xylitol alone did not differ significantly from that of their matched DMEM-HG control group (Figure 1A, B).

\section{Xylitol of $0.45 \%$ provides protection} against the hyperosmotic stimulus-induced increase in intracellular $\mathrm{Ca}^{2+}$ concentration

Hyperosmotic stress induced by $450 \mathrm{mOsm}$ sorbitol was accompanied by a short elevation of intracellular $\mathrm{Ca}^{2+}$ concentration. This elevation $(\mathrm{M}=328.6 \mathrm{nM}, 25 \mathrm{p}=232.0$, $75 \mathrm{p}=602.4$ ) was prevented neither by glycerol nor the lower concentration of xylitol, but it was suppressed by the higher concentration $(0.45 \%)$ of xylitol $(\mathrm{M}=78.76 \mathrm{nM}$, $25 \mathrm{p}=45.92,75 \mathrm{p}=140.72$ ) (Figure 2A). Figure 2 also shows
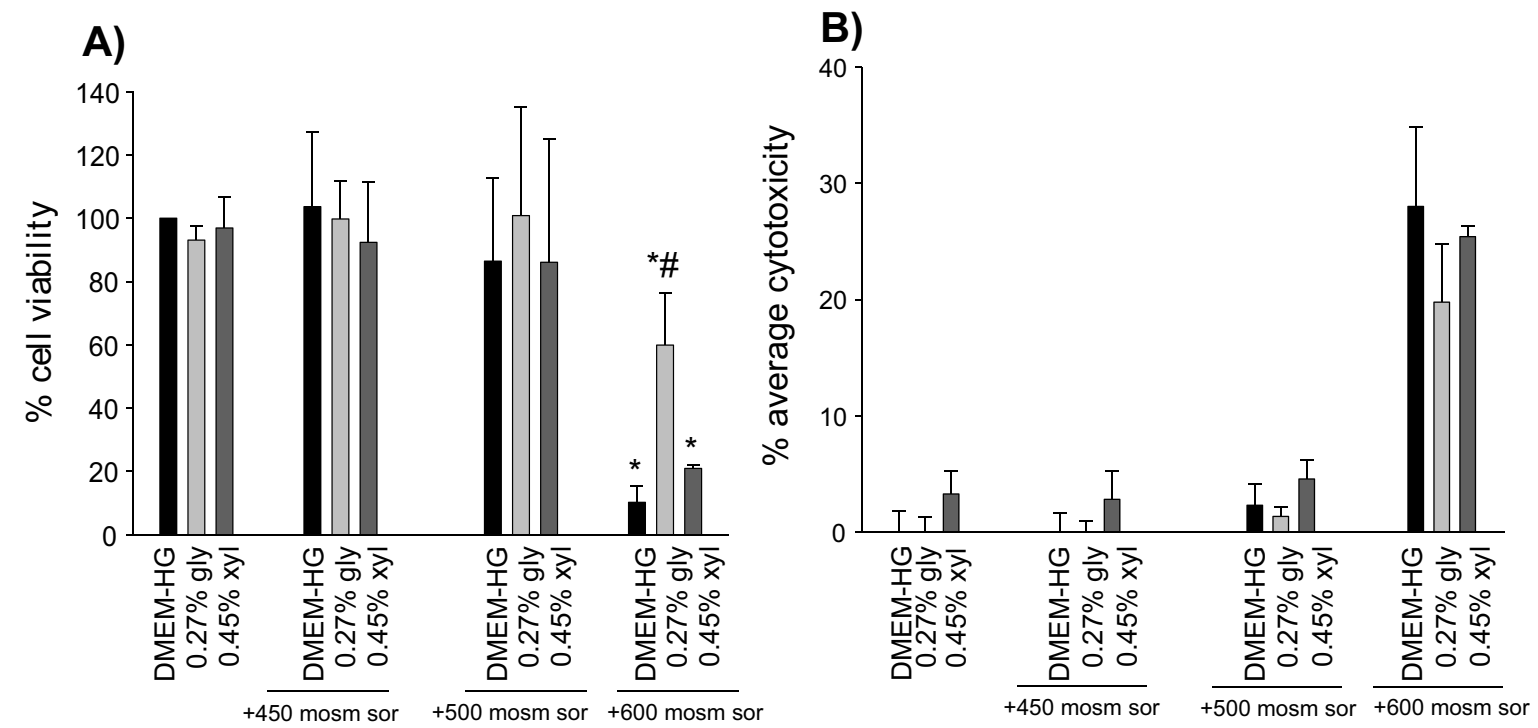

Figure I (A) The effects of glycerol and xylitol on cellular viability in hyperosmotic stress. (B) The effects of polyols in osmotic stress-induced cytotoxicity. Statistical analysis was performed with one-way ANOVA and Holm-Sidak post-hoc test (mean+SD), ${ }^{*} p<0.05$ vs DMEM-HG., \#p<0.05 vs DMEM-HG +600 mOsm sor, $\mathrm{n}=3$. Abbreviations: DMEM-HG, Dulbecco's modified eagle's medium containing $4.5 \mathrm{~g} / \mathrm{L}$ glucose; sor, sorbitol; gly, glycerol; xyl, xylitol. 


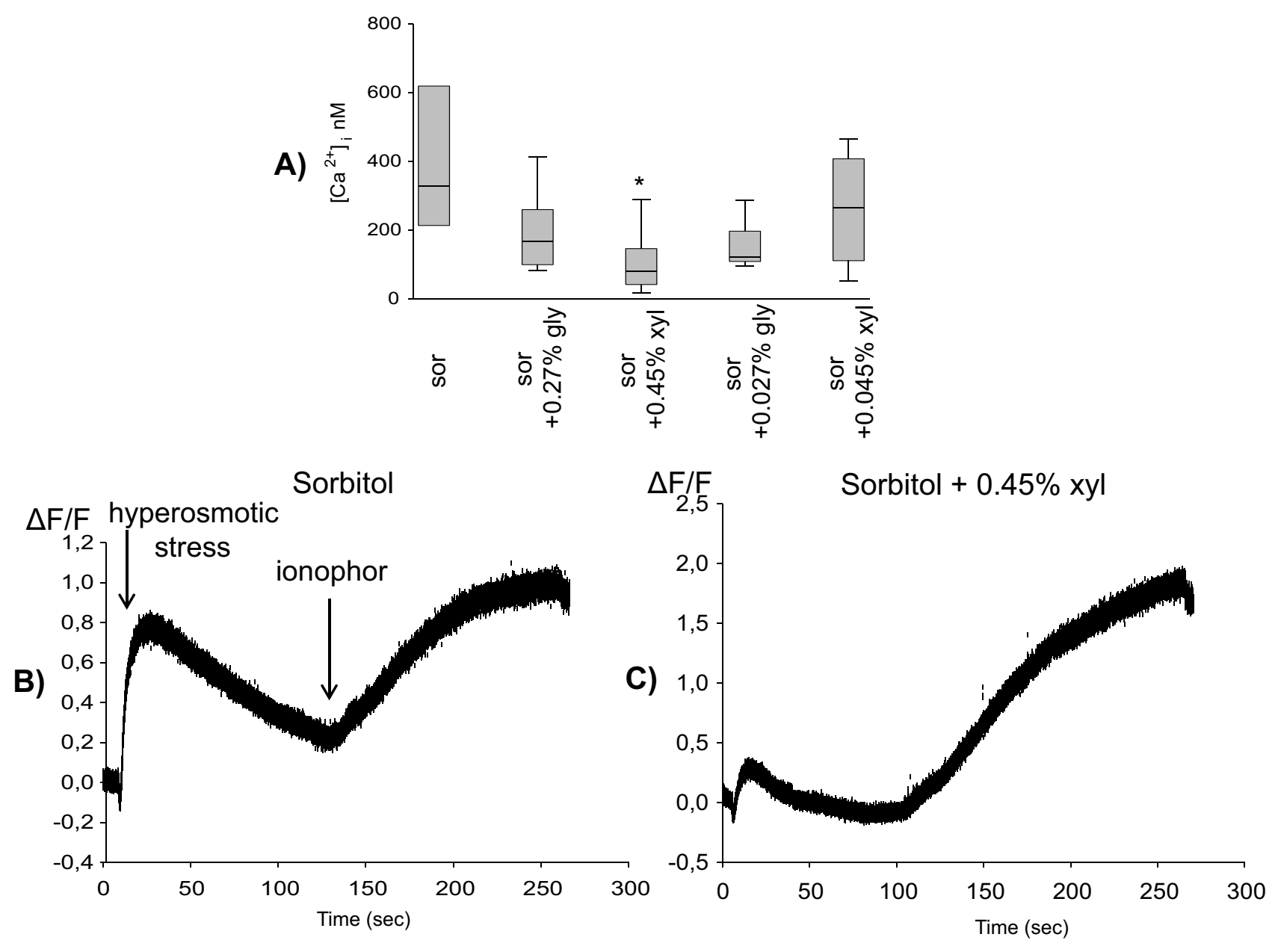

Figure 2 (A) Xylitol protected against the hyperosmotic stimulus-induced increase in intracellular $\mathrm{Ca}^{2+}$ concentration. Statistical analysis was performed with KruskalWallis one-way analysis of variance on ranks, followed by Dunn's method (median, 25 th and 75 th percentile), ${ }^{*} p<0.05$ vs sor, $n=8-10$. (B and $\left.\mathbf{C}\right)$ A representative curve of the relative fluorescence on $450 \mathrm{mOsm}$ sorbitol (B) and additional xylitol-treated group (C).

Abbreviations: sor, sorbitol; gly, glycerol; xyl, xylitol.

two representative curves of this response from the sorbitol-treated (Figure 2B) and the sorbitol and 0.45\% xylitoltreated groups (Figure 2C).

\section{Polyols prevented the elevation in the mRNA expression of inflammatory cytokines and NFAT5 induced by osmotic stress}

The mRNA expression of inflammatory cytokines (TNF- $\alpha$, IL-1 $\alpha$, IL-1 $\beta$, IL-6 and IL-8) and the osmosis-related NFAT5 was measured after 2 and 6 hrs hyperosmotic stress. After $6 \mathrm{hrs}$, no significant changes were detected (data not presented). Following 2 hrs treatment, the cytokine levels of glycerol or xylitol-treated groups were similar to that of the untreated control group. $450 \mathrm{mOsm}$ sorbitol induced considerable increase in IL-1 $\alpha$, IL-1 $\beta$,
IL-8 and NFAT5 expression. Both $0.27 \%$ glycerol and $0.45 \%$ xylitol prevented the elevation in the expression of IL-1 $\alpha$ (Figure 3A). Furthermore, both $0.27 \%$ glycerol and $0.45 \%$ xylitol led to considerably lower expression of IL-8, and the expression levels did not differ significantly from those of untreated control group (Figure 3D). As concerns IL- $1 \beta$ and NFAT5, only $0.27 \%$ glycerol diminished considerably their expression (Figure 3B, C). No significant difference was found among the six study groups in TNF- $\alpha$ and IL-6 expression (data not shown).

\section{Discussion}

ICD is a frequent occupational disorder ${ }^{24}$ which is characterized by impaired barrier function leading to increased TEWL. Water evaporation exposes keratinocytes to a condition of high osmotic pressure. ${ }^{9}$ In our previous animal experiments, sodium lauryl sulfate (SLS)-induced skin irritation resulted 
A)

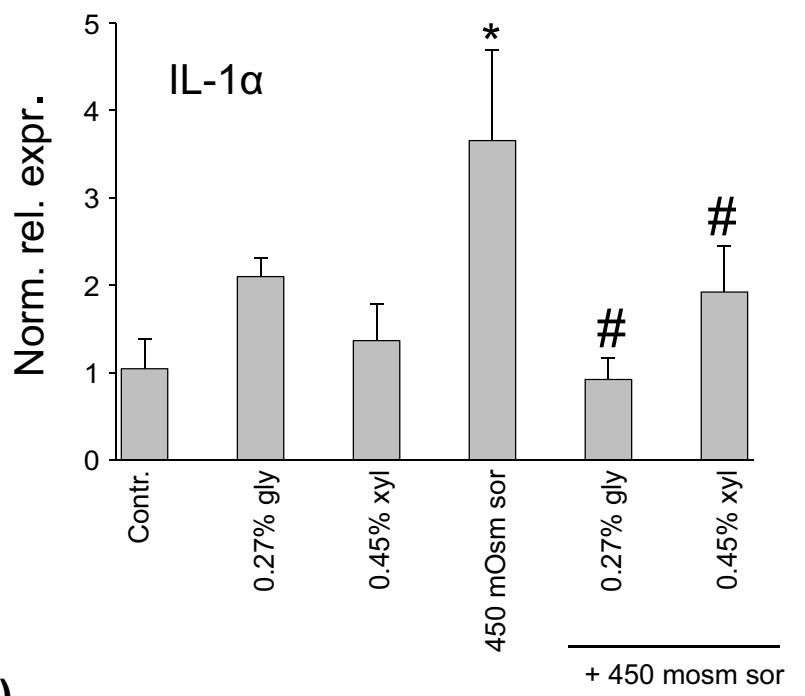

C)

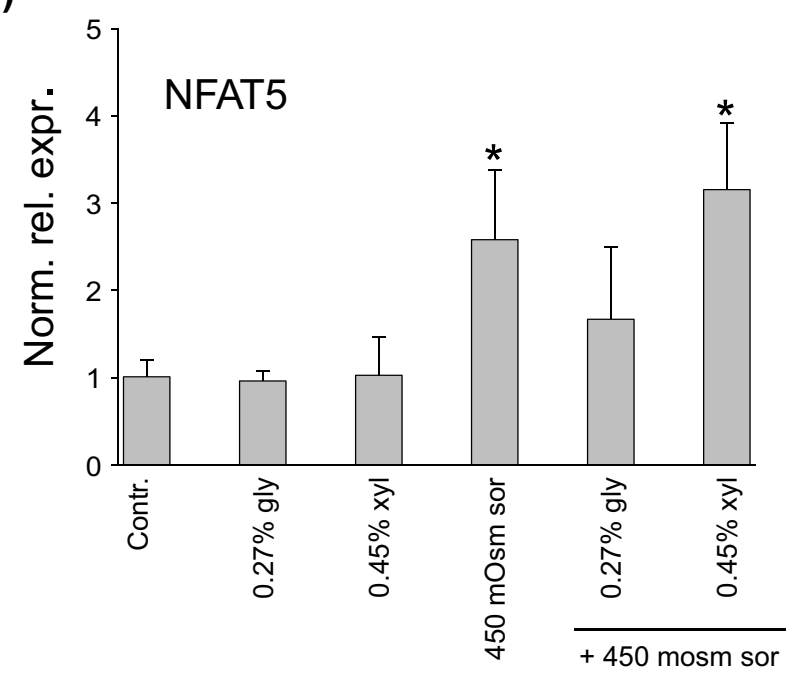

B)

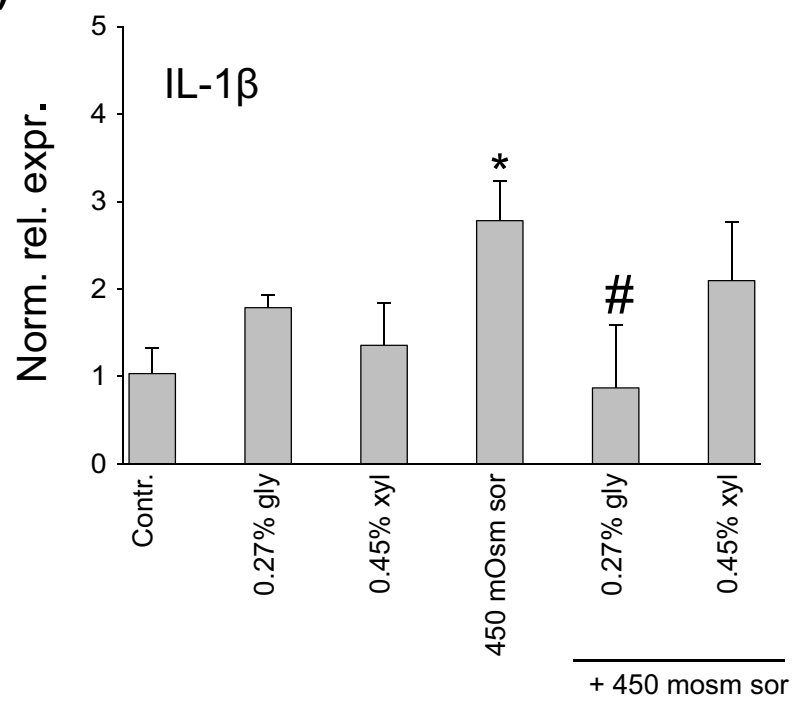

D)

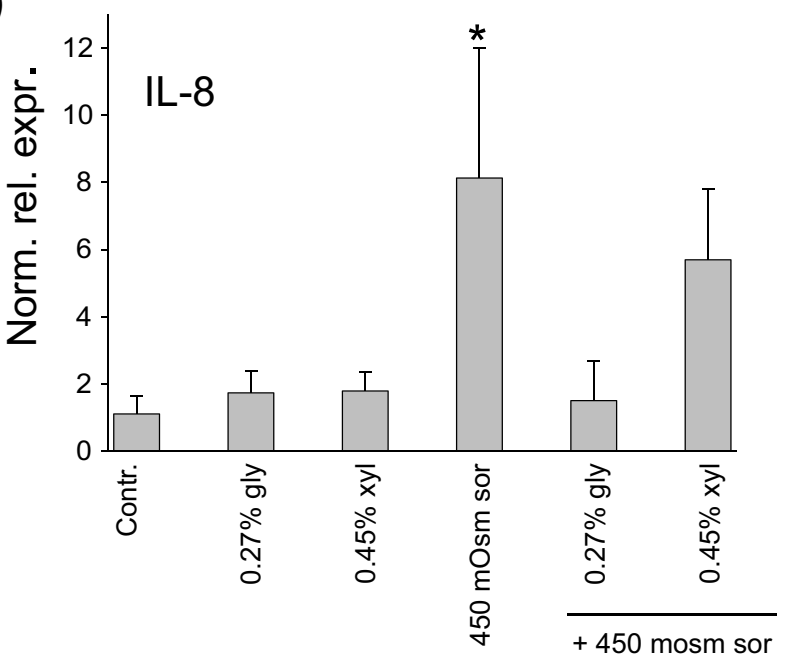

Figure 3 In vitro effects of polyols on (A) IL-I $\boldsymbol{\alpha},(\mathbf{B})$ IL- I $\boldsymbol{\beta},(\mathbf{C})$ NFAT5 and (D) IL-8 expression. The expression of each gene was normalized to the I8S rRNA gene and relative mRNA levels were calculated by the $\Delta \Delta \mathrm{Ct}$ method, compared to the untreated, time-matched control samples. Statistical analysis was performed with one-way ANOVA and $\mathrm{Holm}$ Sidak post-hoc test (mean + SD), ${ }^{*} p<0.05$ vs Contr., $\# p<0.05$ vs 450 mOsm sor, $n=3$ (a-c) and Kruskal-Wallis one-way analysis of variance on ranks, followed by Dunn's method (median, 25th and 75th percentile), $*_{p}<0.05$ vs Contr, $n=3$ (d) Despite the difference in the statistical tests, mean + SD values are shown in all subfigures for uniform presentation. Abbreviations: Norm. rel. expr, normalized relative expression; Contr, control; sor, sorbitol; gly, glycerol; xyl, xylitol.

in the reduction of epidermal thickness ${ }^{17}$ that can be considered as an indirect evidence for osmotic stress. Thus, the present study aimed at the investigation of osmotic challenge potentially accompanying ICD. In response to hyperosmotic stress, organic osmolytes are accumulated by the cells. In the skin, betaine, myoinositol and taurine are important osmolytes and the expression of their transporters (betaine/GABA transporter, sodium/myoinositol transporter and taurine transporter) is induced by osmotic stress. ${ }^{25}$

The anti-irritant and anti-inflammatory effects of glycerol and xylitol have already been demonstrated in animal experiments. ${ }^{17}$ Joint application of glycerol and xylitol increases skin hydration, decreases TEWL, improves biomechanical properties of the skin and induces a higher filaggrin production in the epidermis after 2 weeks of application. ${ }^{18}$ However, their cellular mechanism of action has not been revealed in details. We assumed that these polyols may act as organic osmolytes and therefore may have a role in osmoregulation.

It has been described that the effects of polyols may depend on the applied concentration. ${ }^{17,26}$ Hence, two different concentrations were tested in our in vivo studies ${ }^{16,17}$ and also two different concentrations were chosen for the present experiments, based on previous in vitro results. ${ }^{21}$ According 
to the results of the effect of polyols on $\mathrm{Ca}^{2+}$ concentration in our preliminary experiments, only the higher polyol concentrations were applied in the measurement of cellular viability, cytotoxicity and cytokine expression.

In order to induce osmotic stress, instead of the ionic sodium chloride and the detergent SLS, sorbitol was chosen, which is a metabolically inactive, inert agent. Sorbitol is also a polyol osmolyte such as glycerol and xylitol; however, it has no known protective effect in inflammatory skin conditions, and it is used to induce osmotic stress. ${ }^{8}$

Osmotic challenge influences cellular viability in an osmolarity- and time-dependent manner. ${ }^{4-7}$ Such effect is also characteristic of ICD: severe irritation of the skin (24 hrs exposure to SLS) can induce tissue necrosis in vivo ${ }^{27}$ but milder irritant challenges do not lead to necrosis. ${ }^{28}$ In our experiments, $24 \mathrm{hrs}$ exposure to 450 and $500 \mathrm{mOsm}$ sorbitol did not influence cellular viability and cytotoxicity, but $600 \mathrm{mOsm}$ resulted in a significant decrease in viability as compared to untreated control cells.

However, instead of $600 \mathrm{mOsm}, 450 \mathrm{mOsm}$ osmotic stress was applied to measure intracellular calcium concentration, in order to examine the protective effects of polyols, with the elimination of cell death. According to our pilot study, 450 mOsm hyperosmotic stimulus with sorbitol was sufficient to induce a short elevation of intracellular $\mathrm{Ca}^{2+}$ with a kinetics similar to that of measured by Dascalu et al who applied 500 mOsm sucrose. ${ }^{6}$ Although the exact molecular mechanism is still not fully clarified, it has been described that dihydropiridine-sensitive $\mathrm{Ca}^{2+}$ channels are not affected. ${ }^{6}$ The transient receptor potential vanilloid $1 \mathrm{~b}$ (TRPV1b) non-selective cation channel, which is expressed also by $\mathrm{HaCaT}$ cells, ${ }^{29}$ can be induced by cell shrinking in hypertonicity ${ }^{30}$ and therefore may have a potential role in $\mathrm{Ca}^{2+}$ response. In osmotic stress, increased inositol 1,4,5-trisphosphate (IP3) and diacylglycerol (DAG) synthesis were observed, as well. ${ }^{31}$ TRPV1 can also be activated by $\mathrm{Ca}^{2+32}$ and DAG. ${ }^{33}$ Moreover, IP3 receptors may contribute to $\mathrm{Ca}^{2+}$ influx, too. ${ }^{34}$

Based on literature data, ${ }^{21}$ the applied polyols alone did not influence intracellular $\mathrm{Ca}^{2+}$ concentration. According to our results, xylitol prevented the elevation of intracellular $\mathrm{Ca}^{2+}$ concentration induced by the hyperosmotic sorbitol solution while glycerol did not influence this parameter. Further investigations are necessary to reveal the reason for this difference and the exact mechanism via which xylitol inhibits $\mathrm{Ca}^{2+}$ signal.

In addition to the rapid $\mathrm{Ca}^{2+}$ response, the applied osmotic challenge has longer effects, as well. $2 \mathrm{hrs}$ of exposure to $450 \mathrm{mOsm}$ sorbitol increased the expression of IL- $1 \alpha$, IL- $1 \beta$ and IL- 8 in HaCaT cells. It has been described that cytokine expression elevates in keratinocytes when 500 mOsm of osmotic stimulus is present for $6 \mathrm{hrs} .^{9}$ Cytokine production may originate from the $\mathrm{Ca}^{2+}$ response. ${ }^{35}$ However, in a recent study, pro-inflammatory responses evoked with ATP- or bradykinin-induced elevation of the intracellular $\mathrm{Ca}^{2+}$ concentration could not be suppressed by glycerol or xylitol. Moreover, none of these polyols influenced the subcellular translocation of the $\mathrm{Ca}^{2+}$ dependent protein kinase $\mathrm{C}$ (PKC) $\alpha$. However, xylitol but not glycerol translocated the $\mathrm{Ca}^{2+}$-independent $\mathrm{PKC} \delta .^{36}$ TRPV1 activation can also lead to enhanced cytokine production via direct or indirect NF- $\mathrm{B}$ activation. ${ }^{37}$ Independently from the $\mathrm{Ca}^{2+}$ response, hyperosmotic stress also activates the transcription factor NFAT $5^{5}$ which regulates TNF- $\alpha^{38}$ and can bind the promoter of IL-1 and IL-6. ${ }^{1}$ Thus, elevated expression of NFAT5 might have contributed to the increased cytokine expression in the present study. Our previous in vivo investigations have already shown the anti-inflammatory effect of glycerol and xylitol. ${ }^{16-18}$ However, differences can be found as compared to the present in vitro results. Glycerol and xylitol decreased the mRNA expression of IL- $1 \beta$ and TNF- $\alpha$, but had no effect on the IL- $1 \alpha$ levels in a murine model of ICD. ${ }^{17}$ Several factors may explain the beneficial effects of polyols on cytokine expression. In addition to the prevention of $\mathrm{Ca}^{2+}$ signal and the inhibition of NFAT5 expression, glycerol and xylitol may affect the inflammatory process via stabilizing protein structure. As chaperon osmolytes, these polyols are able to enhance protein folding, thereby assisting in the development of the final structure essential for the optimal enzyme function, and they promote protein-protein and protein-DNA interactions. ${ }^{39}$

Our findings indicate that glycerol provides protection not only against acute inflammation but also against a more serious damage which occurs after a relatively longer timespan. The protective effect of glycerol was found to appear after a 24 hrs exposure to osmotic stress when aquaporin-3 (AQP-3) gene expression shows a peak. ${ }^{40}$ If AQP-3 expression increases at protein level, as well, it provides an enhanced intracellular transport of glycerol. This theory is supported by our observation that cellular viability was ameliorated only when glycerol was continuously available (data not shown).

\section{Conclusion}

The effects of glycerol and xylitol were tested under hyperosmotic condition as an in vitro model of osmotic 
Table 2 The chemical structure, known and novel properties of glycerol and xylitol

\begin{tabular}{|c|c|c|}
\hline & Glycerol & Xylitol \\
\hline Chemical structure & $\mathrm{H}-\left.\right|_{\mathrm{CH}} ^{\mathrm{CH}_{2} \mathrm{OH}}$ & \begin{tabular}{c|c} 
& $\mathrm{CH}_{2} \mathrm{OH}$ \\
$\mathrm{H}$ & $\mathrm{OH}$ \\
$\mathrm{HO}$ & $\mathrm{H}$ \\
$\mathrm{H}$ & $\mathrm{OH}$ \\
& $\mathrm{C} \mathrm{H}_{2} \mathrm{OH}$
\end{tabular} \\
\hline \multirow[t]{3}{*}{ Known properties } & \multicolumn{2}{|c|}{ in vivo anti-inflammatory and anti-irritant effects ${ }^{16-18}$} \\
\hline & $\begin{array}{l}\text { Composition of the bacterial osmo- } \\
\text { lyte system }{ }^{19}\end{array}$ & $\begin{array}{l}\text { Inhibition of TNF- } \alpha \text { and IL-I } \beta \text { expres- } \\
\text { sion in vitro }{ }^{20}\end{array}$ \\
\hline & HLA-DR mRNA suppression ${ }^{21}$ & Filaggrin mRNA upregulation ${ }^{21}$ \\
\hline \multirow{3}{*}{$\begin{array}{l}\text { Novel in vitro features in } \mathrm{HaCaT} \text { keratinocytes exposed to } \\
\text { hyperosmotic stress }\end{array}$} & \multicolumn{2}{|l|}{ Suppression of IL-I $\alpha$} \\
\hline & Amelioration of cell viability & $\begin{array}{l}\text { Prevention of rapid intracellular } \mathrm{Ca}^{2+} \\
\text { signal }\end{array}$ \\
\hline & $\begin{array}{l}\text { Decrease in the expression of IL-I } \beta \\
\text { and NFAT5 }\end{array}$ & \\
\hline
\end{tabular}

stress accompanying ICD and other xerotic skin diseases. The applied polyols supported cell viability, prevented hyperosmosis-induced $\mathrm{Ca}^{2+}$ signal and the expression of inflammatory cytokines. Despite their similar chemical structure, the effect of these polyols displayed differences (Table 2). Hence, joint application of glycerol and xylitol may be a useful therapeutic approach for different skin disorders.

\section{Acknowledgment}

The authors are grateful to the assistants for their valuable contribution to the work.

\section{Disclosure}

The authors report no conflicts of interest in this work.

\section{References}

1. Neuhofer W. Role of NFAT5 in inflammatory disorders associated with osmotic stress. Curr Genomics. 2010;11:584-590. doi:10.2174/ 138920210793360961

2. Tan $\mathrm{CH}$, Rasool S, Johnston GA. Contact dermatitis: allergic and irritant. Clin Dermatol. 2014;32:116-124. doi:10.1016/j.clindermatol.201 3.05 .033

3. Li DQ, Luo L, Chen Z, Kim HS, Song XJ, Pflugfelder SC. JNK and ERK MAP kinases mediate induction of IL-1beta, TNF-alpha and IL-8 following hyperosmolar stress in human limbal epithelial cells. Exp Eye Res. 2006;82:588-596. doi:10.1016/j.exer.2005.08.019
4. Veltmann M, Hollborn M, Reichenbach A, Wiedemann P, Kohen L, Bringmann A. Osmotic induction of angiogenic growth factor expression in human retinal pigment epithelial cells. PloS One. 2016;11: e0147312. doi:10.1371/journal.pone. 0147312

5. Lee JH, Kim M, Im YS, Choi W, Byeon SH, Lee HK. NFAT5 induction and its role in hyperosmolar stressed human limbal epithelial cells. Invest Ophthalmol Vis Sci. 2008;49:1827-1835. doi:10.1167/iovs.07-0624

6. Dascalu A, Matithyou A, Oron Y, Korenstein R. A hyperosmotic stimulus elevates intracellular calcium and inhibits proliferation of a human keratinocyte cell line. J Invest Dermatol. 2000;115:714-718. doi:10.1046/j.1523-1747.2000.00099.x

7. Zhang S, Yanaka A, Tauchi M, et al. Hyperosmotic stress enhances interleukin-1beta expression in helicobacter pylori-infected murine gastric epithelial cells in vitro. $J$ Gastroenterol Hepatol. 2006;21:759-766. doi:10.1111/j.1440-1746.2006.04293.x

8. Rodríguez I, Kaszkin M, Holloschi A, et al. Hyperosmotic stress induces phosphorylation of cytosolic phospholipase $\mathrm{A}(2)$ in $\mathrm{HaCaT}$ cells by an epidermal growth factor receptor-mediated process. Cell Signal. 2002;14:839-848. doi:10.1016/S08986568(02)00031-1

9. Terunuma A, Aiba S, Tagami H. Cytokine mRNA profiles in cultured human skin component cells exposed to various chemicals: a simulation model of epicutaneous stimuli induced by skin barrier perturbation in comparison with that due to exposure to haptens or irritant. J Dermatol Sci. 2001;26:85-93. doi:10.1016/S0923-1811(00)00165-1

10. Magnúsdóttir E, Kalachikov S, Mizukoshi K, et al. Epidermal terminal differentiation depends on B lymphocyte-induced maturation protein-1. Proc Natl Acad Sci U S A. 2007;104:14988-14993. doi:10.1073/pnas.0707323104

11. Wang H, Ferraris JD, Klein JD, Sands JM, Burg MB, Zhou X. PKC- $\alpha$ contributes to high $\mathrm{NaCl}$-induced activation of NFAT5 (TonEBP/ OREBP) through MAPK ERK1/2. Am J Physiol Renal Physiol. 2015;308:F140-148. doi:10.1152/ajprenal.00167.2014 
12. Hiyama A, Gajghate S, Sakai D, Mochida J, Shapiro IM, Risbud MV Activation of TonEBP by calcium controls \{beta\}1,3-glucuronosyltransferase-I expression, a key regulator of glycosaminoglycan synthesis in cells of the intervertebral disc. $J$ Biol Chem. 2009;284:9824-9834. doi:10.1074/jbc.M807081200

13. Feske S. Calcium signalling in lymphocyte activation and disease. Nat Rev Immunol. 2007;7:690-702. doi:10.1038/nri2152

14. Wiig H, Schröder A, Neuhofer W, et al. Immune cells control skin lymphatic electrolyte homeostasis and blood pressure. J Clin Invest. 2013;123:2803-2815. doi:10.1172/JCI60113

15. Fluhr JW, Darlenski R, Surber C. Glycerol and the skin: holistic approach to its origin and functions. $\mathrm{Br} J$ Dermatol. 2008;159:23-34. doi:10.1111/j.1365-2133.2008.08643.x

16. Korponyai C, Kovács RK, Erös G, Dikstein S, Kemény L. Antiirritant properties of polyols and amino acids. Dermatitis. 2011;22:141-146.

17. Szél E, Polyánka $H$, Szabó $K$, et al. Anti-irritant and anti-inflammatory effects of glycerol and xylitol in sodium lauryl sulphate-induced acute irritation. J Eur Acad Dermatol Venereol. 2015;29:2333-2341. doi:10.1111/jdv.12669

18. Korponyai C, Szél E, Behány Z, et al. The effects of locally applied glycerol and xylitol on the hydration, barrier function and morphological parameters of the skin. Acta Derm Venereol. 2017;97:182-187. doi:10.2340/00015555-2493

19. Yancey PH, Clark ME, Hand SC, Bowlus RD, Somero GN. Living with water stress: evolution of osmolyte systems. Science. 1982;217:1214-1222.

20. Han SJ, Jeong SY, Nam YJ, Yang KH, Lim HS, Chung J. Xylitol inhibits inflammatory cytokine expression induced by lipopolysaccharide from Porphyromonas gingivalis. Clin Diagn Lab Immunol. 2005;12:1285-1291. doi:10.1128/CDLI.12.2.280-286.2005

21. Szabó-Papp J, Sós K, Oláh A, et al. Differential effects of common moisturizer polyols on normal human epidermal keratinocytes. $J$ Invest Dermatol. 2012;132:S58.

22. Prorok J, Kovács PP, Kristóf AA, et al. Herpesvirus-mediated delivery of a genetically encoded fluorescent $\mathrm{Ca}(2+)$ sensor to canine cardiomyocytes. J Biomed Biotechnol. 2009;2009:361795. doi: $10.1155 / 2009 / 361795$

23. Paredes RM, Etzler JC, Watts LT, Zheng W, Lechleiter JD. Chemical calcium indicators. Methods San Diego Calif. 2008;46:143-151. doi:10.1016/j.ymeth.2008.09.025

24. Schwensen JF, Friis UF, Menné T, Johansen JD. One thousand cases of severe occupational contact dermatitis. Contact Dermatitis. 2013;68:259-268. doi:10.1111/cod.2013.68.issue-5

25. Warskulat U, Reinen A, Grether-Beck S, Krutmann J, Häussinger D. The osmolyte strategy of normal human keratinocytes in maintaining cell homeostasis. J Invest Dermatol. 2004;123:516-521. doi:10.1111/ j.0022-202X.2004.23313.x

26. Atrux-Tallau N, Romagny C, Padois K, et al. Effects of glycerol on human skin damaged by acute sodium lauryl sulphate treatment. Arch Dermatol Res. 2010;302:435-441. doi:10.1007/ s00403-009-1021-z
27. Erös G, Kurgyis Z, Németh IB, et al. The irritant effects of pharmaceutically applied surfactants. J Surfact Deterg. 2014;17:67-70. doi:10.1007/s11743-013-1444-6

28. Jibry N, Murdan S. In vivo investigation, in mice and in man, into the irritation potential of novel amphiphilogels being studied as transdermal drug carriers. Eur J Pharm Biopharm Off J Arbeitsgemeinschaft Pharm Verfahrenstechnik EV. 2004;58:107-119. doi:10.1016/j.ejpb.2004.02.013

29. Pecze L, Szabó K, Széll M, et al. Human keratinocytes are vanilloid resistant. PLoS One. 2008;3:e3419. doi:10.1371/journal.pone.0003419

30. Sharif Naeini R, Witty MF, Séguéla P, Bourque CW. An N-terminal variant of Trpv1 channel is required for osmosensory transduction. Nat Neurosci. 2006;9:93-98. doi:10.1038/nn1614

31. Rodriguez I, Holloschi A, Kaszkin M, et al. Activation of phospholipase C-gammal in human keratinocytes by hyperosmolar shock without enzyme phosphorylation. Arch Dermatol Res. 2004;295:490-497. doi:10.1007/s00403-004-0457-4

32. Zitt C, Obukhov AG, Strübing C, et al. Expression of TRPC3 in Chinese hamster ovary cells results in calcium-activated cation currents not related to store depletion. J Cell Biol. 1997;138:1333-1341.

33. Venkatachalam K, van Rossum DB, Patterson RL, Ma HT, Gill DL. The cellular and molecular basis of store-operated calcium entry. Nat Cell Biol. 2002;4:E263-272. doi:10.1038/ncb1102-e263

34. Boulay G, Brown DM, Qin N, et al. Modulation of $\mathrm{Ca}(2+)$ entry by polypeptides of the inositol 1,4, 5-trisphosphate receptor (IP3R) that bind transient receptor potential (TRP): evidence for roles of TRP and IP3R in store depletion-activated $\mathrm{Ca}(2+)$ entry. Proc Natl Acad Sci U S A. 1999;96:14955-14960. doi:10.1073/pnas.96.26.14955

35. Szöllősi AG, Vasas N, Angyal Á, et al. Activation of TRPV3 regulates inflammatory actions of human epidermal keratinocytes. J Invest Dermatol. 2018;138:365-374. doi:10.1016/j.jid.2017.11.021

36. Páyer E, Szabó-Papp J, Ambrus L, et al. Beyond the physico-chemical barrier: glycerol and xylitol markedly yet differentially alter gene expression profiles and modify signalling pathways in human epidermal keratinocytes. Exp Dermatol. 2018;27:280-284. doi:10.1111/exd.13493

37. Huang J, Ding L, Shi D, et al. Transient receptor potential vanilloid-1 participates in the inhibitory effect of ginsenoside Rg1 on capsaicin-induced interleukin-8 and prostaglandin E 2 production in HaCaT cells: GRg1 inhibits TRPV1 activation in HaCaT cells. $J$ Pharm Pharmacol. 2012;64:252-258. doi:10.1111/j.20427158.2011.01392.x

38. López-Rodríguez C, Aramburu J, Jin L, Rakeman AS, Michino M, Rao A. Bridging the NFAT and NF-kappaB families: NFAT5 dimerization regulates cytokine gene transcription in response to osmotic stress. Immunity. 2001;15:47-58.

39. Brocker C, Thompson DC, Vasiliou V. The role of hyperosmotic stress in inflammation and disease. Biomol Concepts. 2012;3:345-364. doi:10.1515/bmc-2012-0001

40. Sugiyama Y, Ota Y, Hara M, Inoue S. Osmotic stress up-regulates aquaporin-3 gene expression in cultured human keratinocytes. Biochim Biophys Acta. 2001;1522:82-88. doi:10.1016/S01674781(01)00320-7

\section{Publish your work in this journal}

Clinical, Cosmetic and Investigational Dermatology is an international, peer-reviewed, open access, online journal that focuses on the latest clinical and experimental research in all aspects of skin disease and cosmetic interventions. This journal is indexed on CAS.
The manuscript management system is completely online and includes a very quick and fair peer-review system, which is all easy to use. Visit http://www.dovepress.com/testimonials.php to read real quotes from published authors. 